\title{
Contradições e o limiar de custo-efetividade
}

\author{
Contradictions and the cost-effectiveness threshold
}

\author{
Contradicciones y el umbral de costo-efectividad
}

doi: 10.1590/0102-311X00096117

Por ocasião do trâmite no Senado Federal do Projeto de Lei no 415 de 2015 (https://www25.senado.leg.br/ web/atividade/materias/-/materia/122071), De Soarez \& Novaes discutem e criticam a necessidade de adoção de um limiar de custo-efetividade pelo Brasil na seção Perspectivas de CSP 1. Alguns argumentos apresentados pelas autoras, nos parecem, contraditoriamente, corroborar nossa visão publicada no Jornal Brasileiro de Economia da Saúde 2, de que o limiar é necessário, em especial a restrição ao orçamento da saúde.

Inicialmente, estamos de acordo que a incorporação de tecnologias no Sistema Único de Saúde (SUS) e em outros sistemas universais deva ser baseada em múltiplos critérios, incluindo a confiança nas evidências de eficácia, segurança, barreiras de implementação, impacto orçamentário, ética, equidade e preferências sociais. Entretanto, esses critérios devem também incluir a eficiência da tecnologia, que do ponto de vista econômico, é refletida pela razão do investimento financeiro adicional por anos de vida ajustados pela qualidade (do inglês quality-adjusted life years - QALY) ou sobrevida incremental. A interpretação, contudo, desse critério para a decisão de incorporação só faz sentido se for comparativa, na medida em que os recursos em saúde são escassos e a incorporação de uma tecnologia pode resultar na não incorporação ou até mesmo desincorporação de outras. Dessa forma, as análises de custo-efetividade e custo-utilidade apoiam a decisão dos gestores de incorporar uma tecnologia em saúde desde que sejam interpretáveis de forma clara e transparente, e que sejam combinadas com estudos de impacto orçamentário e outras avaliações multicritério. Nesse sentido, a possibilidade de se contar com mais de um critério desenvolvido com metodologia robusta e factível para o SUS poderia refletir a maturidade do processo de tomada de decisão, inclusive ao coibir as análises subjetivas e a incorporação baseada apenas em comparações com estratégias alternativas, estas sim muitas vezes selecionadas por provedores de tecnologias em saúde com base em seus interesses próprios. Conforme citado pelas autoras, vivemos de fato tempos de restrição orçamentária e imposição de teto para gastos em saúde, e acreditamos que justamente nestas condições as escolhas transparentes e racionais se tornam ainda mais necessárias para a melhor alocação dos já escassos recursos públicos. A falta de transparência nas decisões para o SUS favorece o direcionamento das decisões por interesses meramente políticos ou econômicos. 
Outro ponto relevante para o debate é como definir o limiar. As autoras criticam o atualmente já superado critério proposto pela Organização Mundial da Saúde (OMS). Embora esse critério venha sendo utilizado por muitos autores ${ }^{3}$, inclusive De Soarez \& Novaes, concordamos que se trata de uma generalização difícil de ser adaptada a diferentes países e cenários. Na ausência de um critério próprio, a Comissão Nacional de Incorporação de Tecnologias no SUS (CONITEC) vem aceitando o limiar proposto pela OMS para a adoção de tecnologias custo-efetivas, como foi o caso da incorporação da vacina contra o HPV 3. Em nosso artigo 2, discutimos várias outras formas de decidir pela incorporação, incluindo o custo de oportunidade e as preferências da sociedade, que nos parecem mais justas.

Acreditamos que nossos gestores e as comissões que apoiam suas decisões, como a CONITEC, deveriam ter uma sólida formação para compreender e criticar as avaliações de tecnologias em saúde - incluindo as econômicas - que lhes são apresentadas. A sociedade brasileira também precisa ser informada de forma transparente para compreender o processo e participar da decisão sobre os critérios das decisões, inclusive aqueles para adoção de um limiar.

As autoras declaram não ter conflitos de interesses ou qualquer relação com o Projeto de Lei no 415 de 2015, proposto no Senado Federal.

Marisa da Silva Santos 1

Marcia Pinto 2

Anete Trajman 3

1 Instituto Nacional de Cardiologia, Rio de Janeiro, Brasil.

2 Instituto Nacional de Saúde da Mulher, da Criança e do Adolescente Fernandes Figueira, Fundação Oswaldo Cruz, Rio de Janeiro, Brasil.

3 Instituto de Medicina Social, Universidade do Estado do Rio de Janeiro, Rio de Janeiro, Brasil.

\section{Colaboradores}

Todas as autoras redigiram e revisaram o artigo.
1. De Soarez PC, Novaes HMD. Limiares de custo-efetividade e o Sistema Único de Saúde. Cad Saúde Pública 2017; 33:e00040717.

2. Pinto M, Santos M, Trajman A. Limiar de custo-efetividade: uma necessidade para o Brasil? J Bras Econ Saúde 2016; 8:58-60.

3. Novaes HM, de Soarez PC, Silva GA, Ayres A, Itria A, Rama CH, et al. Cost-effectiveness analysis of introducing universal human papillomavirus vaccination of girls aged 11 years into the National Immunization Program in Brazil. Vaccine 2015; 33 Suppl 1:A135-42.

Recebido em 05/Jun/2017

Aprovado em 13/Jun/2017 